\title{
Effects of thermal and mechanical pretreatments of secondary sludge on biogas production under thermophilic conditions
}

\author{
Mavi Climent ${ }^{\mathrm{a}}$, Ivet Ferrer ${ }^{\mathrm{b}}$, Ma del Mar Baeza ${ }^{\mathrm{c}}$, Adriana Artola ${ }^{\mathrm{a}}$, Felícitas Vázquez ${ }^{\mathrm{b}}$, \\ Xavier Font ${ }^{\mathrm{a}}$
}

${ }^{a}$ Departament d'Enginyeria Química, Escola Tècnica Superior d'Enginyeria, Edifici Q Universitat Autònoma de Barcelona

08193- Bellaterra (Barcelona) Spain

${ }^{\mathrm{b}}$ GIRO Technological Centre

Rambla Pompeu Fabra, 1. 08100 - Mollet del Vallès (Barcelona) Spain

${ }^{\mathrm{c}}$ Grup de Sensors i Biosensors, Departament de Química, Facultat de Ciències,

Edifici C

Universitat Autònoma de Barcelona

08193- Bellaterra (Barcelona) Spain

Corresponding author: Adriana Artola

Departament d'Enginyeria Química, Escola Tècnica Superior d'Enginyeria, Edifici Q

Universitat Autònoma de Barcelona

08193- Bellaterra (Barcelona) Spain

Phone: +34 9358144 80; Fax: +34 935812013

e-mail address: adriana.artola@uab.es

Pre-print of: Climent, M. et al. "Effects of thermal and mechanical pretreatments of secondary sludge on biogas production under thermophilic condicitions" in Chemical engineering journal (Ed. Elsevier), vol. 133, no. 1-3 (Sep. 2007), p.335-342. The final version is available at DOI 10.1016/j.cej.2007.02.020 


\begin{abstract}
Slow degradation of sewage sludge is a disadvantage of anaerobic digestion leading to high sludge retention times in conventional digesters. Hydrolysis has been pointed as the rate limiting step in this process. Thermophilic anaerobic digestion has been proved effectively to reduce the retention time needed for sludge stabilization. Sludge pretreatment has been also proposed as a strategy to accelerate the hydrolytic step. The effectiveness of high and low temperature thermal pretreatment, ultrasonic and microwave pretreatments in secondary sludge disintegration has been studied by means of the increment in filterable volatile solids to total volatile solids ratio (FVS/TVS) respect to untreated sludge. Increments in this parameter ranging from 3 fold for microwave treatment to 9 fold for high temperature thermal treatment have been obtained. Biogas production under thermophilic $\left(55^{\circ} \mathrm{C}\right)$ conditions for treated and untreated secondary sludge has also been evaluated. In spite of the values of FVS/TVS ratio obtained for all the treatments studied, no differences in biogas production were observed when high temperature thermal treatment, ultrasonic and microwave treatments are compared with untreated sludge. A 50\% increment in biogas production was observed for low temperature $\left(70^{\circ} \mathrm{C}\right)$ thermally treated sludge. This type of treatment has been pointed as a predigestion step enhancing biological activity of some thermophilic hydrolytic bacteria.
\end{abstract}

Keywords: Thermophilic anaerobic digestion; biogas production; microwave pretreatment secondary sludge; thermal pretreatment; ultrasound pretreatment. 


\section{INTRODUCTION}

Anaerobic digestion is a sludge treatment process used in many municipal wastewater treatment plants (MWWTP) to stabilize organic matter. Mass reduction, methane production and, improved dewatering properties of the treated sludge are the main features of the process [1]. Slow degradation of sewage sludge is a disadvantage of anaerobic digestion leading to a retention time in conventional digesters of about 20 days. This fact implies significant space requirements and the construction of large equipment in MWWTP. Anaerobic digestion may be carried out under mesophilic and thermophilic conditions. In general, mesophilic anaerobic digestion of sewage sludge is more widely used compared to thermophilic digestion, mainly because of the lower energy requirements and higher stability of the process [2]. On the other hand, thermophilic anaerobic digestion provides sludge hygienization, increases methane production and reduces the retention time needed for sludge treatment [3].

Anaerobic digestion process follows four major steps: hydrolysis, acidogenesis, acetogenesis and methanogenesis. Hydrolysis is the rate limiting step of the overall process in the case of sludge degradation [2]. During hydrolysis both solubilization of particulate matter and biological decomposition of organic polymers to monomers or dimers take place. Thermal, chemical, biological and mechanical processes as well as different combinations of them have been studied as possible pretreatments to accelerate sludge hydrolysis [4-6]. These pretreatments cause the lysis or disintegration of sludge cells permitting the release of intracellular matter that becomes more accessible to anaerobic microorganisms. This fact improves the overall digestion process velocity and the degree of sludge degradation thus reducing anaerobic digester retention time and increasing methane production rates $[7,8]$. 
Efficiency of the pretreatments is commonly evaluated by means of chemical parameters (increment in soluble chemical oxygen demand (SCOD), increment in soluble protein concentration (SPC) and increment in filterable volatile solids concentration (FVS)) and biogas production [9-11]. Biogas production tests (BPT) are commonly undertaken under mesophilic conditions because as mentioned above, anaerobic digestion is mostly applied under mesophilic conditions. Thus, there is a lack of knowledge on the effect of sludge pretreatments on thermophilic anaerobic digestion. Few references have been found on the effect of sludge pretreatment on biogas production. Stuckey and McCarty [12] reported the results of BPT under mesophilic $\left(35^{\circ} \mathrm{C}\right)$ and thermophilic $\left(55^{\circ} \mathrm{C}\right)$ conditions for untreated and thermally treated $(175-$ $275^{\circ} \mathrm{C}$ ) sludge. The authors found significantly higher biogas production under mesophilic conditions for both types of sludge and a slight increment in biogas production under thermophilic conditions if untreated and treated sludge at $175-200^{\circ} \mathrm{C}$ are compared. They argue that different rates of reaction in the two temperature regimes explain their results.

Thermal pretreatment has been studied using a wide range of temperatures ranging from 60 to $270^{\circ} \mathrm{C}$. Temperatures over $200^{\circ} \mathrm{C}$ have been found responsible for refractory compound formation $[7,12]$. The most common treatment temperatures are between 60 and $180^{\circ} \mathrm{C}$. Treatments applied at temperatures under $100^{\circ} \mathrm{C}$ are considered as low temperature thermal treatments [2].

In high temperature thermal treatments, treatment time appeared to have less effect compared to that of temperature, with common values in the range 30-60 $\mathrm{min}$ [13]. Hight temperature treatments are usually applied to sludge by heat exchangers or by steam injection [7]. Valo et al. [13] reported increments in SCOD of around $25 \%$ 
and $60 \%$ after thermal treatment of secondary sludge at $130^{\circ} \mathrm{C}$ and $170^{\circ} \mathrm{C}$ respectively. These authors also evaluated the biogas production of the thermally treated sludge in batch tests at mesophilic temperatures and observed increments of $21 \%$ and $45 \%$ in biogas production respectively compared to untreated sludge. The most significant drawback of this treatment is the high requirement of energy that it involves. Some authors have pointed out that the energetic expense can be balanced due to the increment in sludge biodegradability and to the use of sludge residual heat in the maintaintenance of digester temperature [11].

Low temperature thermal treatment has been pointed out as an effective treatment for increasing biogas production from both primary and secondary sludge [14]. However, few references are found in the literature although this treatment implies lower energy consumption. Some authors have concluded that thermal treatment applied at temperatures around $70^{\circ} \mathrm{C}$ enhance biological activity of some thermophilic bacteria population with optimum activity temperatures in the high values of the thermophilic range [15]. Thus, low temperature thermal treatment may be considered as a predigestion step.

Mechanical sludge disintegration methods are generally based on the disruption of microbial cell walls by shear stresses. Stirred ball mills, high pressure homogenisers and mechanical jet smash techniques have been used for mechanical treatment application although the most used technique is sludge sonication [5,7]. Sonication is a combination of different phenomena: chemical reactions using radicals, pyrolysis, combustion and shearing. In fact, both ultrasonic vibration and bulk temperature rise contribute to the treatment efficiency [16]. Mechanisms of the ultrasonic process are influenced by three factors: supplied energy, ultrasonic frequency and nature of the treated material. It has 
been shown that degradation of excess sludge is more efficient using low frequencies [8]. Ultrasonic treatment of secondary sludge has been studied by different authors using SCOD increment. Values ranging from 10 to $90 \%$ of increment were observed when the specific energy applied increased from 1,000 to $100,000 \mathrm{~kJ} \mathrm{~kg} \mathrm{TS}^{-1}$ (kg of total solids in the sludge) $[8,17,18]$. An increment in biogas production of around $40 \%$ (batch mode, $37^{\circ} \mathrm{C}$ ) was found for sludge pretreated at $14,000 \mathrm{~kJ} \mathrm{~kg} \mathrm{TS}^{-1}$ while no difference in biogas production was observed when pretreated sludge at $1,000 \mathrm{~kJ} \mathrm{~kg} \mathrm{TS}^{-}$ ${ }^{1}$ was compared to untreated sludge [8].

In addition to thermal and mechanical treatments widely reported, the use of microwaves appears as an alternative treatment for sludge disintegration. Microwaves are an electromagnetic radiation with an oscillation frequency of 0.3 to $300 \mathrm{GHz}$ which causes both heat generation and changes in secondary and tertiary structure of proteins of microorganisms. Although microwave irradiation has been reported as a fast method for cell lysis, its application as a sludge pretreatment process in anaerobic digestion is scarcely mentioned $[19,20]$. Park et al. [20] studied the degree of sludge disintegration by microwave treatment by means of SCOD/COD ratio reporting an increment in a factor of 8.5 at microwave irradiation energy of $600 \mathrm{~kJ} \mathrm{~L}^{-1}$.

The objective of this work is to study the efficiency of high and low temperature thermal pretreatment, ultrasound pretreatment and microwave pretreatment in sludge disintegration. The effect of pretreatment is studied and compared using in all tests secondary sludge from the same MWWTP. The efficiency of the different processes is evaluated and compared by means of a chemical parameter, filterable to total volatile solids ratio (FVS/TVS), and the biogas production of pretreated sludge under thermophilic $\left(55^{\circ} \mathrm{C}\right)$ conditions. 
Influence of temperature and contact time in the efficiency of high temperature thermal treatment has also been systematically studied using the experimental design technique.

\section{MATERIALS AND METHODS}

\section{Sludge}

Secondary sludge from a biological MWWTP sited in La Llagosta (Barcelona, Spain) was used in the study. After collection, sludge was stored at $4^{\circ} \mathrm{C}$ until its utilization (maximum storage time, 2 days). Characteristics of secondary sludge were: Total Solids (TS): $38-49 \mathrm{~kg} \mathrm{~m}^{-3}$, Total Volatile Solids (TVS): $28-38 \mathrm{~kg} \mathrm{~m}^{-3}$, Suspended Solids (SS): 36-46 $\mathrm{kg} \mathrm{m}^{-3}$, Volatile Suspended Solids (VSS): 28-36 $\mathrm{kg} \mathrm{m}^{-3}$.

\section{Disintegration evaluation}

The increment in the Filterable Volatile Solids: Total Volatile Solids ratio (FVS/TVS) has been chosen as the chemical parameter to evaluate the degree of disintegration of pretreated sludge. This increment is expressed as a percentage following equation 1.

$(\mathrm{FVS} / \mathrm{TVS})$ increment $(\%)=\frac{(\mathrm{FVS} / \mathrm{TVS})_{\mathrm{t}}-(\mathrm{FVS} / \mathrm{TVS})_{\mathrm{u}}}{(\mathrm{FVS} / \mathrm{TVS})_{\mathrm{u}}} \cdot 100$

where $(\mathrm{FVS} / \mathrm{TVS})_{\mathrm{t}}$ and $(\mathrm{FVS} / \mathrm{TVS})_{\mathrm{u}}$ are the filterable volatile solids:total volatile solids ratio found in treated and untreated sludge respectively.

\section{Pretreatment conditions}

High temperature thermal treatment 
An autoclave (P Selecta Autester - E) was used for this treatment. Sludge was treated under different combinations of temperature (from 110 to $134^{\circ} \mathrm{C}$ ) and time (from 20 to $90 \mathrm{~min}$ ). Temperature and time ranges were limited by the technical characteristics of the autoclave. $0.5 \mathrm{~L}$ of sludge were used in each experiment. The time at which the desired temperature was reached in the autoclave was considered as time 0 .

A central composite experimental design was used to evaluate the influence of the factors temperature $\left(\mathrm{X}_{\text {temp }}\right)$ and time $\left(\mathrm{X}_{\mathrm{time}}\right)$ on thermal treatment effectiveness [21]. Three levels were considered for each of the two factors. The experimental design technique is based on the evaluation of the coefficients for the variables considered fitting a polynomial function $\mathrm{Y}_{\mathrm{i}}$ which is proposed to describe the system under study. A second order polynomial expression including interactions was chosen to relate the factors considered with the response variable as shown in equation 2:

$\mathrm{Y}_{\mathrm{i}}=\mathrm{b}_{0}+\mathrm{b}_{1} \cdot \mathrm{X}_{\mathrm{temp}}+\mathrm{b}_{2} \cdot \mathrm{X}_{\mathrm{time}}+\mathrm{b}_{11} \cdot \mathrm{X}_{\mathrm{temp}}^{2}+\mathrm{b}_{22} \cdot \mathrm{X}_{\mathrm{time}}{ }^{2}+\mathrm{b}_{12} \cdot \mathrm{X}_{\mathrm{temp}} \cdot \mathrm{X}_{\mathrm{time}}$

where $\mathrm{X}_{\text {temp }}$ corresponds to temperature $\left({ }^{\circ} \mathrm{C}\right), \mathrm{X}_{\text {time }}$ to time (min) and $\mathrm{Y}_{\mathrm{i}}$ to the increment $(\%)$ in the ratio FVS/TVS.

Values considered for the two factors were normalized from -2 to 2 using equation 3 to improve the comparison of the coefficients and the visualization of the effects of each factor on the response surface obtained:

$X_{i}^{*}=\frac{X_{i}-c_{x}}{d_{x}} d^{*}$ 
where $\mathrm{X}_{\mathrm{i}}^{*}$ and $\mathrm{X}_{\mathrm{i}}$ are the normalized and experimental values of the different levels of each factor respectively, $c_{x}$ represents the central value, $d_{x}$ the distance between the limits of the experimental range and $\mathrm{d}^{*}$ the maximum distance between the normalized values.

F-test was applied to statistically validate the quality of the fitting of the proposed expression to the experimental data. Optimization of the polynomial function was carried out by a quasi Newton method using IMSL® libraries included in Microsoft Fortran Powerstation ${ }^{\circledR} 4.0$.

\section{Low temperature thermal treatment}

The temperature chosen to apply this treatment was $70^{\circ} \mathrm{C}$ according to the work of Skiadas et al. [14]. Treatment time has been established in 9, 24, 48 and 72 hours. Higher contact times were not considered because of the significant increase in the energy requirements that these values imply.

$500 \mathrm{~mL}$ of sludge were poured in a beaker and placed in a thermostatic bath used to maintain the desired temperature. Sludge was mechanically agitated during treatment time to ensure temperature homogeneity of the sludge sample.

\section{Ultrasonic treatment}

An ultrasonic homogenizer LABSONIC $2000-\mathrm{U}(300 \mathrm{~W}, 20 \mathrm{kHz})$ was used. $0.08 \mathrm{~L}$ of sludge were placed in a $0.1 \mathrm{~L}$ plastic beaker. The beaker was placed in a cooling bath to minimize sludge temperature increment during the treatment. Treatment was done at constant power and different sonication times to provide different values of the specific energy from 1,000 to $100,000 \mathrm{~kJ} \mathrm{~kg} \mathrm{SS}^{-1}$. Specific energy $\left(\mathrm{E}_{\mathrm{s}}\right)$ is defined as: 
$\mathrm{E}_{\mathrm{s}}=\frac{\mathrm{P} \cdot \mathrm{t}}{\mathrm{V} \cdot \mathrm{SS}}$

where $\mathrm{P}$ is the ultrasonic power $(\mathrm{W}), \mathrm{t}$ is the sonication time (s), $\mathrm{V}$ is the sample volume (L) and SS is the concentration of suspended solids in the sludge sample $\left(\mathrm{kg} \mathrm{L}^{-1}\right)$.

\section{Microwave treatment}

A domestic microwave oven, SHARP R-234 (800 W, $2450 \mathrm{MHz})$, was used for sludge disintegration. $0.5 \mathrm{~L}$ of sludge were placed in a $1 \mathrm{~L}$ Pyrex beaker partially covered to avoid sludge losses caused by hot spot formation. Experiments were performed at 800 and $400 \mathrm{~W}$ and at increasing times for each power value till sludge boiling (from 180 to $300 \mathrm{~s}$ at $800 \mathrm{~W}$ and from 240 to $600 \mathrm{~s}$ at $400 \mathrm{~W}$ ). Values for $\mathrm{E}_{\mathrm{s}}$ applied in each experiment were calculated with the data proposed.

\section{Analytical methods}

All the analysis were performed in triplicate. TS and TVS of sludge samples were determined before and after treatment according to Standard Methods [22]. Other sludge samples (before and after treatment) were centrifuged (7000 rpm, $25 \mathrm{~min}$ ) and filtered (glass microfiber filters, Albet FV-C $47 \mathrm{~mm} ; 1.2 \mu \mathrm{m}$ pore). The filtrate obtained was used to determine TFS and FVS (Standard Methods).

Volatile Fatty Acids (VFA) concentration was determined by gas chromatography (Perkin-Elmer AutoSystem XL Gas Chromatograph) with a flame ionization detector (FID) and a column HP Innowax $30 \mathrm{~m} \times 0.25 \mathrm{~mm} \times 0.25 \mu \mathrm{m}$. 


\section{Biogas production tests}

Biogas production tests (BPT) were performed in batch mode under thermophilic conditions $\left(55^{\circ} \mathrm{C}\right)$ using $0.3 \mathrm{~L}$ bottles $\left(\mathrm{SIGG}^{\circledR}\right)$ placed in a P Selecta incubator. The bottles were modified in order to guarantee hermetic conditions and to allow inside pressure to be easily measured at different times by means of a SMC Pressure Switch manometer (1.02 bar) [23]. $50 \mathrm{~g}$ of sludge were placed in a bottle where $100 \mathrm{~g}$ of thermophilic anaerobic sludge were added as inoculum. Differences in biogas production were evaluated comparing the biogas production from treated and untreated sludge samples. Tests were done in triplicate. Three bottles containing only inoculum were used as a blank test. Biogas production was evaluated daily until biogas production was negligible (32 days). Values of biogas production reported are net values i.e. volume of biogas obtained from treated or untreated sludge minus volume of biogas produced by the inoculum.

Initial biogas production rate $\left(\mathrm{L} \mathrm{d}^{-1}\right)$ was calculated as the slope of the straight line fitting the values of biogas produced during the initial 10 days of the test.

\section{RESULTS AND DISCUSSION}

\section{High temperature thermal treatment}

The effect of thermal treatment on sludge disintegration was first studied on the increment in the FVS/TVS ratio and then on the biogas production. An experimental design technique was applied. Two factors (time and temperature) and three levels for each factor were considered. Nine experiments were necessary to cover the 
experimental domain. Replicates of the central point were also done. Values of the response variable (FVS/TVS ratio) and factor levels (normalized values in parenthesis) are summarized in Table 1.

As can be seen in Table 1, thermal treatment had a positive effect in sludge disintegration under all the conditions assayed, leading to significant increments in FVS/TVS ratio.

Values in Table 1 were adjusted to a second order polynomial expression including interactions as presented in equation 2. The expression obtained is presented in equation 5. The value of the regression coefficient $\left(\mathrm{r}^{2}\right)$ was 0.9007.

$Y_{i}=815.96+225.42 \cdot X_{\text {temp }}+239.53 \cdot X_{\text {time }}+13.83 \cdot X_{\text {temp }}^{2}+4.13 \cdot X_{\text {time }}^{2}+149.17 \cdot X_{\text {temp }} \cdot X_{\text {time }}$

F-test was used to statistically validate the proposed polynomial model. The analysis of variance demonstrated that the effects of thermal treatment can be well described by the polynomial model proposed in equation 5 . Two $\mathrm{F}_{\text {ratio }}$ were calculated, $\mathrm{F}^{1}$ related to the influence of the factors and $\mathrm{F}^{2}$ related to the lack of fit. The results show that $F_{\text {ratio }}$ is significant for the regression $\left(F_{\text {exp }}^{1}=7.25>F_{\text {tab }}^{1}=6.26\right)$, this means that the factor effect is significant with a confidence of $95 \%$. In addition, the $\mathrm{F}_{\text {ratio }}$ is not significant for the lack of fit $\left(F_{\text {exp }}^{2}=9.01<F_{\text {tab }}^{2}=215.7\right)$ which means that the lack of fit is due mainly to the purely experimental uncertainty. Experimental values obtained for $\%$ increment in FVS/TVS ratio and the response surface corresponding to the polynomial model are presented in Figure 1. 
Values of the coefficients of the first order terms $\left(X_{\text {temp }}\right.$ and $\left.X_{\text {time }}\right)$ indicated that the two factors considered (temperature and time) affected the treatment results in the same extend evaluated in terms of FVS/TVS ratio. Temperature and time have a positive effect in FVS/TVS ratio, thus at increasing values of both factors the response variable will also increase. Besides, interaction between factors $\left(X_{\text {temp }} \cdot X_{\text {time }}\right.$ term) was as significant as the factors themselves. This result is in disagreement with that presented by Valo et al. [13] who determined that time had less influence than temperature in the thermal treatment of sludge. However, in that work, the effectiveness of thermal treatment was evaluated by means of SCOD concentration. A $25 \%$ increment in SCOD concentration was obtained when sludge was pretreated at $130^{\circ} \mathrm{C}$ during 30 minutes. A $30 \%$ increment was reached at the same temperature when treatment time was 60 min. A $60 \%$ increment in SCOD was reported at $170^{\circ} \mathrm{C}$ independently of the time of treatment.

The polynomial expression obtained for FVS/TVS ratio was used to determine the optimal conditions for the thermal treatment of secondary sludge by means of an optimization program based on a quasi-Newton method. These conditions were established as $134^{\circ} \mathrm{C}$ and 90 min which correspond to the maximum values for temperature and time that can be reached with the autoclave used. However, it should be noticed that these optimal conditions imply a significant consumption of energy. Tanaka et al. [24] determine that temperatures within 115 and $150^{\circ} \mathrm{C}$ applied for 1 hour to wastewater sludge lead to a $15 \%$ increment in sludge solubilization (measured as COD). No differences in this temperature range where observed. A temperature of $180^{\circ} \mathrm{C}$ was necessary to reach solubilization values around $30 \%$. 
Biogas production tests were done for both secondary sludge and secondary sludge thermally pretreated under optimal conditions. Final biogas production (volume) and initial biogas production rate were determined and are summarised in Table 2. No significant differences were observed between the values obtained for the two parameters when evaluated for treated and untreated sludge.

\section{Low temperature thermal treatment}

Thermal treatment was also applied to secondary sludge at $70^{\circ} \mathrm{C}$ during $9,24,48$ and 72 h. As stated in the introduction, low temperature thermal treatment has been pointed as a predigestion step, enhancing the biological activity of some hydrolytic bacteria [15]. For this reason, in addition to the value of the \% increment in FVS/TVS ratio, the concentration of VFA in the sludge after treatment time was also evaluated. Results for these two parameters, the production of biogas (L) and the initial rate of biogas production $\left(\mathrm{L} \mathrm{d}^{-1}\right)$ are summarised in Table 3 for the four treatment times tested. Values are also reported for untreated sludge to allow comparison.

As can be seen in Table 3, for all times tested low temperature thermal treatment increased both FVS/TVS ratio and VFA concentration. Values obtained for the FVS/TVS ratio are very similar for the sludge treated during 9, 24 and $48 \mathrm{~h}$, being the value for $24 \mathrm{~h}$ slightly higher than the others. FVS/TVS ratio at $72 \mathrm{~h}$ of treatment was clearly lower. The same tendency is observed for biogas production. Significant increments in this parameter are observed when untreated sludge is compared to treated sludge at 9, 24 and $48 \mathrm{~h}$, the highest difference observed for sludge treated during $9 \mathrm{~h}$ $(174 \mathrm{~mL})$. Biogas production for sludge treated for the longest time $(72 \mathrm{~h})$ was almost equal to that of untreated sludge. Values of VFA concentration may explain this fact: 
VFA concentration clearly increased with treatment time reaching a value of $4.85 \mathrm{~g} \mathrm{~L}^{-1}$ for sludge pretreated for $72 \mathrm{~h}$. We hypothesize that this VFA concentration may be inhibiting microbial activity to some extent leading to a lower production of biogas (no values of inhibitory VFA concentration values under thermophilic conditions were found in the literature).

No differences were observed between the values calculated for the initial biogas production rate.

Thus, best conditions for the application of low temperature thermal treatment were established at $9 \mathrm{~h}$ since it produced the highest biogas production and implied the lowest consumption of energy. However, it should be bear in mind that best conditions for continuous operation should be evaluated and will depend on the capacity of the anaerobic reactor for inflow VFA degradation.

\section{Ultrasonic treatment}

As in thermal treatment, the effect of ultrasounds on secondary sludge was studied in terms of FVS/TVS ratio. The same ultrasonic power $(300 \mathrm{~W})$ was applied to different sludge samples with same volume and suspended solids concentration $(0.08 \mathrm{~L}$ and $37 \mathrm{~g}$ $\mathrm{L}^{-1}$, respectively) at varying treatment times (from 10 to $987 \mathrm{~s}$ ) to reach specific energy values covering $1,000-100,000 \mathrm{~kJ} \mathrm{~kg} \mathrm{SS}^{-1}$ range. A minimum specific energy of 1,000 $\mathrm{kJ} \mathrm{kg} \mathrm{TS}{ }^{-1}$ was considered since it had been reported that this is the minimal energy necessary to break sludge cells while sludge flocs size was reduced at lower specific energies [8].

Results of ultrasonic treatment are shown in Figure 2 where the values of the increment in FVS/TVS ratio are presented for each value of the specific energy applied 
to the sludge $\left(\mathrm{E}_{\mathrm{s}}\right)$ in $\mathrm{kJ} \mathrm{kg} \mathrm{SS}^{-1}$. An increment in the values of FVS/TVS ratio can be observed even at low values of $\mathrm{E}_{\mathrm{s}}$. These values increased strongly when $\mathrm{E}_{\mathrm{s}}$ rose from 1,000 to $20,000 \mathrm{~kJ} \mathrm{~kg} \mathrm{SS}^{-1}$ while for specific energies over $20,000 \mathrm{~kJ} \mathrm{~kg} \mathrm{SS}^{-1}$ smaller increments were detected referred to the increment in the amount of energy applied. The tendency of values obtained for FVS/TVS ratio is similar to those reported by other investigators using other chemical parameters such as the COD disintegration degree $[17,18]$.

As a consequence of ultrasound action on the treated sludge, an increment in the temperature of the sludge under treatment is observed even if a cooling bath is used to avoid evaporation. A $60^{\circ} \mathrm{C}$ maximum temperature increment was registered for the maximum $\mathrm{E}_{\mathrm{s}}$ value tested. Therefore, the effect of ultrasonic treatment may be considered as a joint effect of ultrasound itself and the raise in sludge temperature.

On the basis of these results, a specific energy of $40,000 \mathrm{~kJ} \mathrm{~kg} \mathrm{SS}^{-1}$ was chosen as the optimal for ultrasonic treatment of secondary sludge. A 5 fold increment on FVS/TVS ratio was obtained under these conditions. A higher value was obtained at $100,000 \mathrm{~kJ} \mathrm{~kg} \mathrm{SS}^{-1}$, but the energy required is too high that does not justify the difference observed in FVS/TVS ratio value when compared to that obtained at 40,000 $\mathrm{kJ} \mathrm{kg} \mathrm{SS}^{-1}$ (60\% of increment in the energy applied leads to $30 \%$ increment in FVS/TVS value). Other authors [16] found that a specific energy of 48,000 kJ/kg of total solids was necessary to achieve significant increments in the ratio soluble to total COD. Tiehm et al. [1] establish a treatment time of $64 \mathrm{~s}$ using a high performance ultrasound reactor $(3.6 \mathrm{~kW})$ as optimum value for a subsequent sludge digestion treatment. The parameters used were sludge disintegration, COD in sludge supernatant and biogas production. 
Biogas production test was also undertaken for secondary sludge pretreated by ultrasounds under optimal conditions. Final biogas production (volume) and initial biogas production rate were determined and are summarised in Table 2. As in the case of high temperature thermal treatment, no significant differences were observed between the values obtained for the two parameters when evaluated for treated and untreated sludge.

\section{Microwave treatment}

Microwave treatment was applied to secondary sludge under two fixed microwave power values (400 and $800 \mathrm{~W}$ ) at different times to determine the specific energy that provokes sludge boiling. Treatment times slightly over 10 minutes at $400 \mathrm{~W}$ and 5 minutes at $800 \mathrm{~W}$ were enough for sludge boiling. Sludge samples with the same volume and suspended solids concentration $\left(0.5 \mathrm{~L}\right.$ and $37 \mathrm{~g} \mathrm{~L}^{-1}$, respectively) were treated.

Table 4 presents the values obtained for FVS/TVS ratio for the sludge treated at 400 and $800 \mathrm{~W}$ for each value of the specific energy applied $\left(\mathrm{kJ} \mathrm{kg} \mathrm{SS}^{-1}\right)$. As it can be observed, a significant increment in FVS/TVS ratio values was obtained at all the specific energies applied. The higher the specific energy applied, the higher the increments. A slight difference is observed if the results obtained at the two microwave power values are compared for the same specific energy although this difference does not follow a clear trend (a lower value of FVS/TVS was obtained for microwave power of $800 \mathrm{~W}$ at $\mathrm{E}_{\mathrm{s}}$ of $7,800 \mathrm{~kJ} \mathrm{~kg} \mathrm{SS}{ }^{-1}$ compared to $400 \mathrm{~W}$, while higher values were obtained for $\mathrm{E}_{\mathrm{s}}$ values of 10,400 and $13,000 \mathrm{~kJ} \mathrm{~kg} \mathrm{SS}^{-1}$. 
The maximum specific energy that can be applied in the considered conditions without sludge boiling $\left(13,000 \mathrm{~kJ} \mathrm{~kg} \mathrm{SS}^{-1}\right)$ has been considered as the optimal value for microwave treatment to be applied to secondary sludge. A microwave power of $400 \mathrm{~W}$ applied for $600 \mathrm{~s}(10 \mathrm{~min})$ or $800 \mathrm{~W}$ for $300 \mathrm{~s}(5 \mathrm{~min})$ is necessary to reach this specific energy.

As for ultrasonically pretreated sludge, a biogas production test was also undertaken for sludge treated by microwaves under conditions established as optimal for this treatment. The same result obtained for high temperature thermal treatment and ultrasonic treatment was reached: no significant differences were observed between the values of biogas production and initial production rate obtained for treated and untreated sludge (values in Table 2).

\section{Comparison of the pretreatment processes studied}

Optimal conditions chosen for each treatment and values of FVS/TVS, VFA concentration, biogas production and initial biogas production rate obtained under those conditions are summarized in Table 2. As it can be seen, all treatments improve the values of FVS/TVS ratio. Maximum values obtained for microwave treatment are the lowest compared to ultrasonic and thermal treatments. It has to be considered that compared to ultrasonic treatment, less energy is applied in the case of microwave per $\mathrm{kg}$ SS. High temperature thermal treatment presents the best value for FVS/TVS ratio.

In reference to biogas production, only low temperature thermal treatment lead to an increment in the biogas volume obtained in comparison to untreated sludge. We hypothesize that thermophilic conditions itself may accelerate the hydrolytic step of sludge digestion concealing the possible effect of the majority of the pretreatments 
applied. As suggested by other researchers, low temperature thermal treatment may be assimilated to a biological treatment enhancing the activity of thermophilic bacteria with the optimal activity around $70^{\circ} \mathrm{C}$, thus within the thermophilic range of operation [15]. On the other hand, the possible effect of anaerobic sludge acclimation to a sludge input of different characteristics as is pretreated sludge should be considered. Further work is being undertaken in this direction. A study on the effect of pretreated sludge on biogas production in a continuous pilot scale digester is now in progress.

As stated above, scarce references on the study of the effects of sludge pretreatments on biogas production in batch mode under thermophilic conditions have been found for comparison. Skiadas et al. [14] found significant differences in biogas production under thermophilic conditions after low temperature thermal pretreatment operating in continuous mode in comparison with untreated sludge. Under the same operating conditions, Gavala et al. [2] found no differences in methane production between treated and untreated sludge.

In reference in the increment in the concentration of VFA that the applied pretreatment provokes, no relationship has been found between this parameter, the increment in FVS/TVS and biogas production. As reported in Table 2, a $20 \%$ increment in VFA concentration was detected for the sludge pretreated using microwaves which equals in biogas production to raw sludge and ultrasonically pretreated sludge (no difference in VFA concentration between them was observed).

Initial biogas production rate was estimated from the slope of the straight line fitting the first 10 days of process in the production vs time curves. No significant differences were found between untreated and treated secondary sludge for any of the treatments applied. 
It is important to point out that time and temperature established as best conditions for low temperature thermal treatment would ensure sludge hygienisation that will be mandatory according to European future legislation to allow its utilization in agriculture or soil benefit [25].

However in addition to the results obtained in terms of biogas production and sludge solubilization an economic evaluation should be performed taking into consideration all the factors implied in full scale operation (thermal inertia, maintenance of the digester temperature, possible uses of the residual heat, etc.) before the implementation of a sludge pre-treatment process.

\section{CONCLUSIONS}

Thermal (high and low temperature), ultrasonic and microwave treatments are effective in secondary sludge solubilization as reflected in the increment of FVS/TVS ratio of treated sludge. The lowest values for this parameter were observed for microwave treatment. Microwave, scarcely reported as sludge treatment prior to anaerobic digestion, has been demonstrated as effective method for sludge solubilization with sludge boiling point as a limit for the specific energy applied.

Time and temperature have similar influence on the performance of high temperature thermal treatment as well as the combined effect of the two parameters as derived from the coefficients of the polynomial model that results of the experimental design proposed.

Biogas production and biogas production rate determined under thermophilic batch conditions seem not to be affected by sludge pretreatment at high temperature, with microwaves or ultrasound. Thus, an increment in organic matter solubilization 
reflected by an increment in the ratio FVS/TVS cannot be directly related to an enhancement of the anaerobic digestion of secondary sludge in terms of biogas production in batch mode.

On the other hand, low temperature $\left(70^{\circ} \mathrm{C}\right)$ thermal pretreatment influences positively the production of biogas under thermophilic conditions. This type of treatment seems to enhance the biological activity of some thermophilic bacteria being considered as a biological pretreatment (predigestion step).

An accurate economic study should be performed to balance all the possible benefits and drawbacks of sludge pre-treatment.

\section{ACKNOWLEDGEMENTS}

The authors wish to thank the financial support provided by the Spanish "Ministerio de Ciencia y Tecnología" and FEDER (REN2002-00926/TECNO).

\section{REFERENCES}

[1] A. Tiehm, K. Nickel, U. Neis, The use of ultrasound to accelerate the anaerobic digestion of sewage sludge, Wat. Sci. Tech. 36 (1997) 121-128.

[2] H.N. Gavala, U. Yenal, I.V. Skiadas, P. Westermann, B.K. Ahring, Mesophilic and thermophilic anaerobic digestion of primary and secondary sludge. Effect of pre-treatment at elevate temperature, Wat. Res. 37 (2003) 4561-4572.

[3] B.K. Ahring, Status on science and application of thermophilic anaerobic digestion, Wat. Sci. Tech. 30 (1994) 241-249. 
[4] Y.C. Chiu, C.N. Chang, J.G. Lin, S.J. Huang, Alkaline and ultrasonic pretreatment of sludge before anaerobic digestion, Wat. Sci. Tech., 36 (1997) 155162.

[5] M.P.J. Weemaes, W. Verstraete, Evaluation of current wet sludge disintegration techniques, J. Chem. Technol. Biotechnol. 73 (1998) 83-92.

[6] J. Kim, C. Park, T.H. Kim, M. Lee, S. Kim, S.W. Kim, J. Lee, Effects of various pretreatments for enhanced anaerobic digestion with waste activated sludge, J. Biosci. Bioeng. 95 (2003) 271-275.

[7] J.A. Müller, Pretreatment processes for the recycling and reuse of sewage sludge, Wat. Sci. Tech. 42 (2000) 167-174.

[8] C. Bourgrier, H. Carrère, J.P. Delgenès, Solubilisation of waste-activated sludge by ultrasonic treatment, Chem. Eng. J. 106 (2005) 163-169.

[9] U. Baier, P. Schmidheiny, Enhanced anaerobic degradation of mechanically disintegrated sludge, Wat. Sci. Tech. 36 (1997) 137-143.

[10] H.B. Choi, K.Y. Hwang, E.B. Shin, Effects on anaerobic digestion of sewage sludge pre-treatment, Wat. Sci. Tech. 35 (1997) 207-211.

[11] R.T. Haug, T.J. LeBrun, L.D. Tortorici, Thermal pretreatment of sludges - a field demonstration, J. Wat. Poll. Control Fed. 55 (1983) 23-34.

[12] D.C. Stuckey, P.L. McCarty, The effect of thermal pre-treatment on the anaerobic biodegradability and toxicity of waste activated sludge, Wat. Res. 18 (1984) 13431353.

[13] A. Valo, H. Carrère, J.P. Delgenès, Thermal, chemical and thermo-chemical pretreatment of waste activated sludge for anaerobic digestion, J. Chem. Technol. Biotechnol. 79 (2004) 1197-1203. 
[14] I.V. Skiadas, H.N. Gavala, J. Lu, B.K. Ahring, Thermal pretreatment of primary and secondary sludge at $70^{\circ} \mathrm{C}$ prior to anaerobic digestion. In Anaerobic Digestion 2004: Anaerobic bioconversion. Answer for sustainability, Proceedings of the $10^{\text {th }}$ World Congress, Volume 2, Montreal (Canada), 2004.

[15] H.B. Nielsen, Z. Mladenovska, P. Westermann, B.K. Ahring, Comparison of twostage thermophilic $\left(68^{\circ} \mathrm{C} / 55^{\circ} \mathrm{C}\right)$ anaerobic digestion with one-stage thermophilic $\left(55^{\circ} \mathrm{C}\right)$ digestion of cattle manure, Biotechnol. Bioeng. 86 (2004) 291-300.

[16] C.P. Chu, C. Bea-Ven, G.S. Liao, D.S. Jean, D.J. Lee, Observations on changes in ultrasonically treated waste activated sludge, Wat. Res. 35 (2001) 1038-1046.

[17] G. Lehne, J. Müller, J. Schwedes, Mechanical desintegration of sewage sludge, Wat. Sci. Tech. 43 (2001) 19-26.

[18] J. Müller, G. Lehne, J. Schwedes, S. Battenberg, R. Näveke, J. Kopp, N. Dichtl, A. Scheminski, R. Krull, D.C. Hempel, Disintegration of sewage sludges and influence on anaerobic digestion, Wat. Sci. Tech. 38 (1998) 425-433.

[19] S. Banik, S. Bandyopadhyay, S. Ganguly, Bioeffects of microwave - a brief review, Biores. Technol. 87 (2003) 155-159.

[20] B. Park, J.H. Ahn, J. Kim, S. Hwang, Use of microwave pretreatment for enhanced anaerobiosis of secondary sludge, Wat. Sci. Tech. 50 (2004) 17-23.

[21] G.E.P. Box, W.G. Hunter, J.S. Hunter, Statistics for experimenters, John Wiley and Sons Ltd., New York (1978).

[22] APHA-AWWA-WEF, Standard Methods for the examination of water and wastewater, $20^{\text {th }}$ edition, American Public Health Association, American Water Works Association, Water Environmental Federation, Washington (1999). 
[23] I. Ferrer, O. Fornés, O. Ferrer, M.A. Gordillo, X. Font, Sistema efectivo y económico para la determinación de la producción de biogás en ensayos en discontinuo, Tecnol del Agua 253 (2004) 50-54.

[24] S. Tanaka, T. Kobayashi, K. Kamiyama, M.L.N. Signey Bildan, Effects of thermochemical pre-treatment of the anaerobic digestion of waste activated sludge, Wat. Sci. Tech. 35 (1997) 209-215.

[25] European Commission, Draft Discussion Document for the ad hoc meeting on biowastes and sludges. Directorate General for the Environment, ENV.A2 (2003). http://www.compost.it/materiali/2003 12_18biowaste directive.pdf. 


\section{Tables}

Table 1. Time and temperature conditions (normalized values in parenthesis) corresponding to the different experiments undertaken to evaluate thermal treatment effectiveness and values obtained for the increment in FVS/TVS ratio (\%)

\begin{tabular}{|c|c|c|c|}
\hline Experiment & $\begin{array}{c}\text { Temperature } \\
\left({ }^{\circ} \mathrm{C}\right)\end{array}$ & $\begin{array}{l}\text { Time } \\
(\min )\end{array}$ & $\begin{array}{c}\text { FVS/TVS } \\
(\% \text { incr })\end{array}$ \\
\hline A & $110(-2)$ & $55(0)$ & $464 \pm 16$ \\
\hline B & $116(-1)$ & $38(-0.97)$ & $383 \pm 19$ \\
\hline $\mathrm{C}$ & $116(-1)$ & $73(1.03)$ & $429 \pm 25$ \\
\hline $\mathrm{D}$ & $122(0)$ & $20(-2)$ & $306 \pm 9$ \\
\hline E1 & $122(0)$ & $55(0)$ & $913 \pm 22$ \\
\hline $\mathrm{E} 2$ & $122(0)$ & $55(0)$ & $808 \pm 31$ \\
\hline $\mathrm{F}$ & $122(0)$ & $90(2)$ & $1,410 \pm 33$ \\
\hline $\mathrm{G}$ & $128(1)$ & $38(-0.97)$ & $814 \pm 29$ \\
\hline $\mathrm{H}$ & $128(1)$ & $73(1.03)$ & $1,441 \pm 50$ \\
\hline I & $134(2)$ & $55(0)$ & $1,104 \pm 34$ \\
\hline
\end{tabular}


Table 2. Optimal conditions established for the studied pretreatments and values obtained for increment in FVS/TVS ratio, increment in VFA concentration, biogas production and biogas production rate for untreated and treated secondary sludge

\begin{tabular}{|c|c|c|c|c|c|}
\hline Pretreatment & $\begin{array}{c}\text { Pretreatment } \\
\text { conditions }\end{array}$ & $\begin{array}{l}\text { FVS/TVS } \\
\text { (\% incr.) }\end{array}$ & $\begin{array}{l}\text { VFA } \\
\text { conc. } \\
\text { (\% incr.) }\end{array}$ & $\begin{array}{c}\text { Biogas } \\
\text { production } \\
\text { (L) }\end{array}$ & $\begin{array}{l}\text { Initial biogas } \\
\text { production } \\
\text { rate }\left(\mathrm{L} \mathrm{d}^{-1}\right)\end{array}$ \\
\hline Untreated & & & & $0.33 \pm 0.02$ & 0.028 \\
\hline $\begin{array}{l}\text { Thermal, high } \\
\text { temperature }\end{array}$ & $\begin{array}{l}\mathrm{T}=134^{\circ} \mathrm{C} ; \\
\mathrm{t}=90 \mathrm{~min}\end{array}$ & $914 \pm 5$ & n.d. ${ }^{*}$ & $0.33 \pm 0.02$ & 0.030 \\
\hline $\begin{array}{l}\text { Thermal, low } \\
\text { temperature }\end{array}$ & $\begin{array}{c}\mathrm{T}=70^{\circ} \mathrm{C} ; \\
\mathrm{t}=9 \mathrm{~h}\end{array}$ & $751 \pm 36$ & $43 \pm 5$ & $0.52 \pm 0.07$ & 0.027 \\
\hline Ultrasonic & $\begin{array}{l}E_{\mathrm{s}}=40,000 \\
\mathrm{~kJ} \mathrm{~kg} \mathrm{SS}{ }^{-1}\end{array}$ & $504 \pm 4$ & 0 & $0.33 \pm 0.01$ & 0.030 \\
\hline Microwave & $\begin{array}{l}E_{\mathrm{s}}=13,000 \\
\mathrm{~kJ} \mathrm{~kg} \mathrm{SS}{ }^{-1}\end{array}$ & $311 \pm 3$ & 20 & $0.30 \pm 0.02$ & 0.026 \\
\hline
\end{tabular}

not determined 
Table 3. Results obtained for untreated and pretreated secondary sludge at $70^{\circ} \mathrm{C}$ (low temperature thermal treatment) during different times.

\begin{tabular}{lcccc}
\hline Pretreatment & FVS/TVS & VFA & Biogas & Initial biogas \\
time $(\mathrm{h})$ & $(\%$ increment $)$ & concentration & production & production \\
& & $(\%$ increment $)$ & $(\mathrm{L})$ & rate $\left(\mathrm{L} \mathrm{d}^{-1}\right)$ \\
\hline Untreated & & $0.33 \pm 0.02$ & 0.028 \\
9 & $751 \pm 36$ & $43 \pm 5$ & $0.52 \pm 0.07$ & 0.027 \\
24 & $817 \pm 27$ & $176 \pm 11$ & $0.46 \pm 0.04$ & 0.036 \\
78 & $771 \pm 14$ & $1180 \pm 57$ & $0.46 \pm 0.01$ & 0.038 \\
72 & $583 \pm 6$ & $2078 \pm 500$ & $0.297 \pm 0.004$ & 0.033 \\
\hline
\end{tabular}


Table 4. Values of FVS/TVS ratio obtained after microwave treatment applied to secondary sludge, microwave power and time of treatment

\begin{tabular}{cccc}
\hline Microwave & $\mathrm{E}_{\mathrm{s}}$ & time & FVS/TVS \\
power $(\mathrm{W})$ & $\left(\mathrm{kJ} \mathrm{kg} \mathrm{SS}^{-1}\right)$ & $(\mathrm{s})$ & $(\%$ incr $)$ \\
\hline 400 & 520 & 240 & $164 \pm 14$ \\
& 7,800 & 360 & $260 \pm 15$ \\
& 10,400 & 480 & $281 \pm 2$ \\
& 13,000 & 600 & $285 \pm 9$ \\
& 7,800 & 180 & $211 \pm 24$ \\
& 10,400 & 240 & $294 \pm 8$ \\
& 13,000 & 300 & $311 \pm 3$ \\
\hline
\end{tabular}




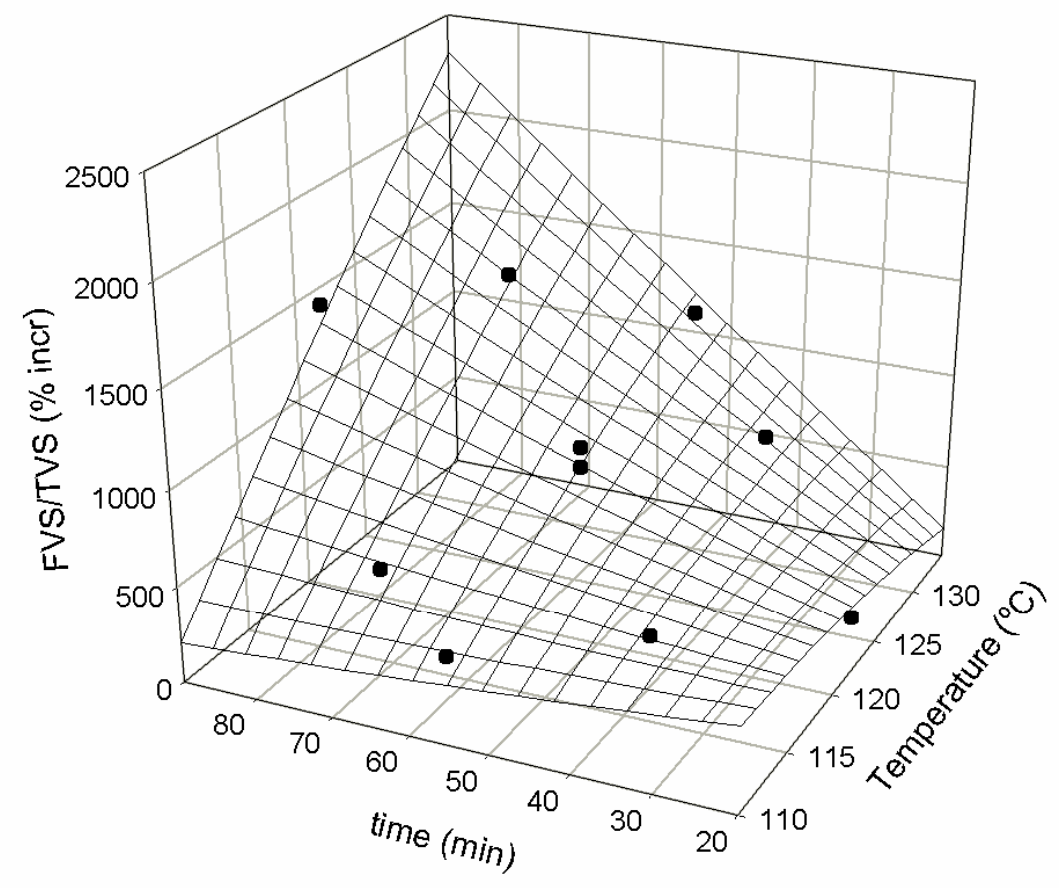

Figure 1. Values obtained for \% increment FVS/TVS ratio after thermal treatment of secondary sludge (dots) under different conditions of time and temperature and polynomial fit to the experimental points (surface). 


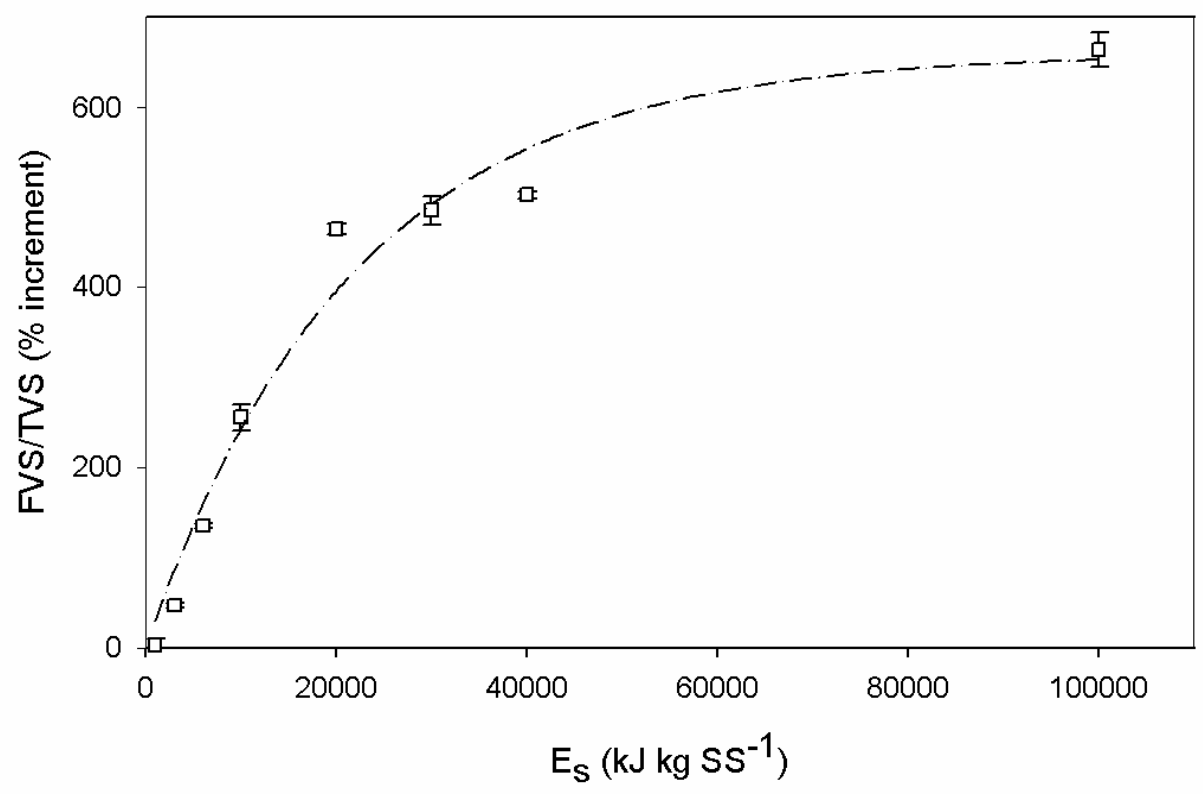

Figure 2. Increment (\%) in FVS/TVS ratio values obtained after ultrasonic treatment of secondary sludge for different specific energies applied (Ultrasonic power, $300 \mathrm{~W}$ ). 